\title{
Development of a mine dewatering and pit slope depressurisation review process
}

\author{
E Reano Piteau Associates Peru S.A.C., Peru \\ G Beale Piteau Associates UK Ltd, UK \\ J Dowling Piteau Associates, USA \\ LC Tejada Freeport-McMoRan Inc., USA \\ M Lacey Freeport-McMoRan Inc., USA
}

H Hazwezwe Freeport-McMoRan Inc., USA

\begin{abstract}
Most major open pit mines eventually require some form of active depressurisation in order to support geomechanical performance. Often, the overall or inter-ramp factor or safety will only remain within acceptable bounds if specific groundwater levels and pore pressures are achieved during mine plan implementation. In an active mine, there is almost always risk that actual groundwater pressure conditions will not comply with the slope design requirements, which elevates the risk of slope instability. This paper reviews some of the main factors that can cause pit slope pore pressures to deviate from design and offers a framework for evaluation and management of risk in-pit-slope depressurisation programs along with practical examples.
\end{abstract}

Keywords: instability slope, groundwater pore pressures, review matrix

\section{Introduction}

Most large open pit mines eventually require some form of proactive depressurisation in order to support desired Factor of Safety (FoS) for the inter-ramp and overall slope design angles. The impact of groundwater on pit wall stability and the role of pore pressure on slope design has been extensively discussed and documented including Beale \& Read (2013) and Beale (2018). Whether start-up greenfield mine development or deepening and expansion of older generation open pits, most slopes are designed to the steepest achievable angles while maintaining an acceptable FoS. Commonly, these objectives involve the assumption that the rock mass and important structures in the design sectors are either dry and not impacted by groundwater, or will contain a prescribed groundwater regime that can only be met with the planning and implementation of proactive pit slope depressurisation measures.

During actual mine sinking and development of the slope sectors, groundwater will almost always be encountered, and a pore pressure regime will develop and evolve behind the pit walls. Additional water or solution may enter the geologic and structural framework of the pit slopes via recharge sourced from mining operations and process activities in the surrounding areas. Oftentimes, the actual 'as-encountered' groundwater conditions in the pit slope will deviate from those assumed or implemented in the slope design. A conceptual example comparing design assumed groundwater levels and actual encountered groundwater levels is shown in Figure 1 and is based on simple hydrostatic assumptions. Figure 2 shows a picture example of pore pressure induced slope instability in an open pit mine. 


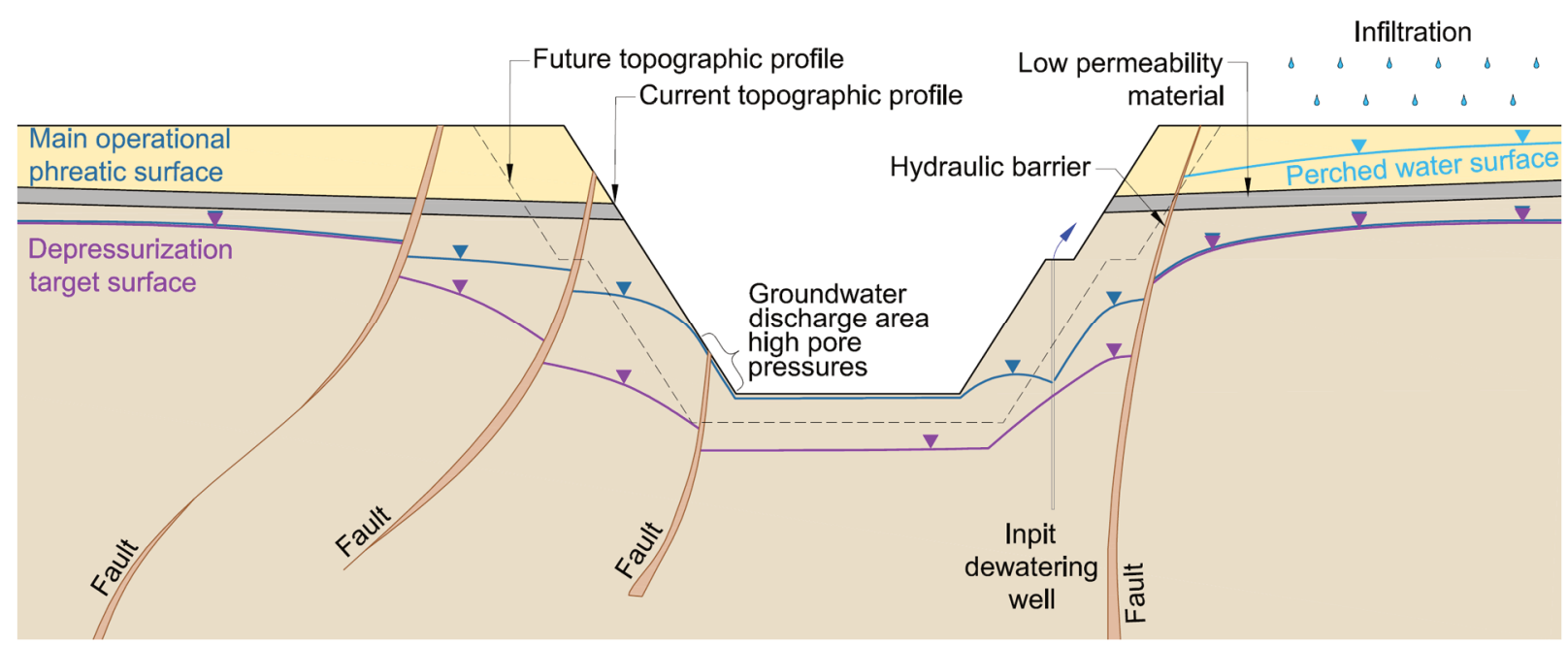

Figure 1 Illustrative pit slope cross-section showing groundwater requirements in the design and actual 'as-encountered' conditions

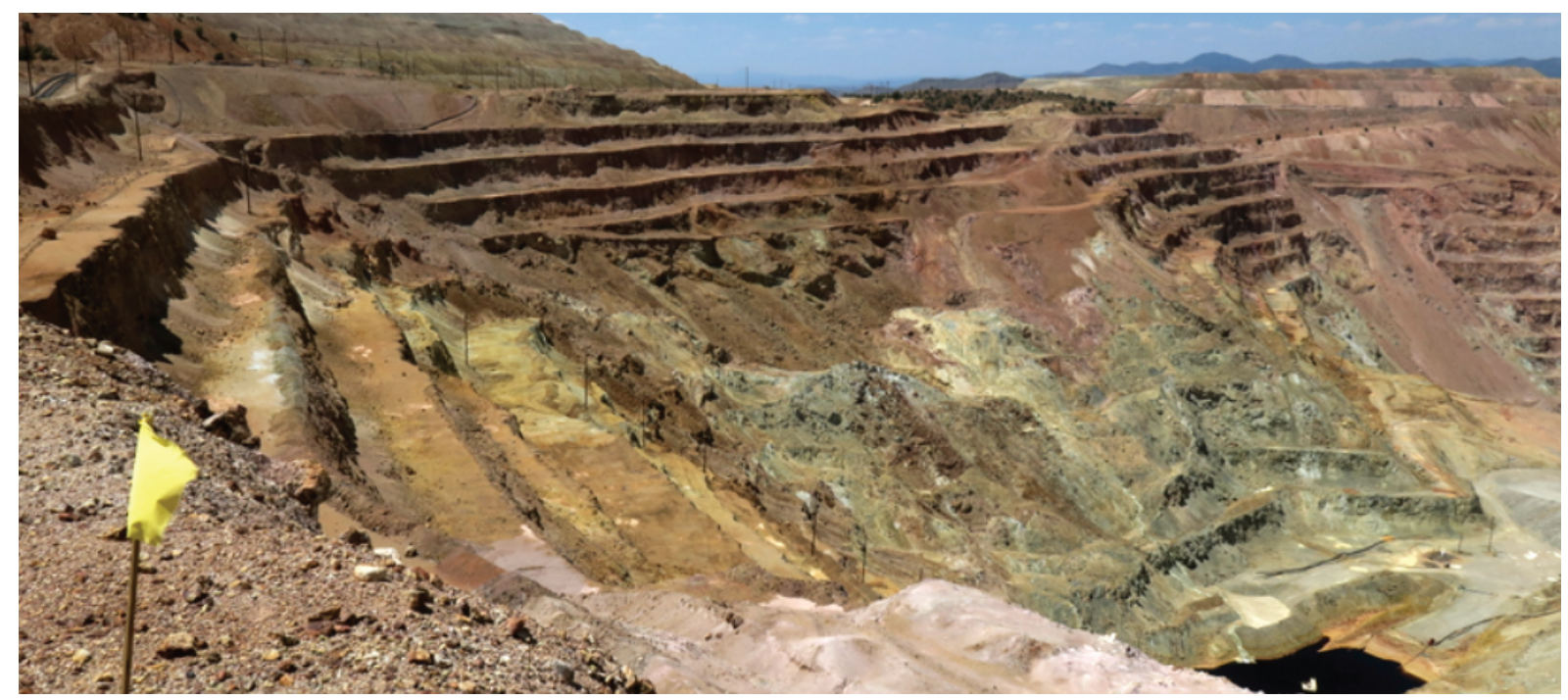

Figure 2 Example slope instability due to the unplanned presence of groundwater; confidential site

It is well documented (Read \& Stacey 2011; Beale \& Read 2013) that unexpected or unplanned groundwater and pore pressure contributes to most significant inter-ramp and overall slope instability. This always results in very significant cost to the mine plan, with impacts often involving slope flattening or unloading to remediate the slope movement, deferral or loss of ore, loss of critical mining infrastructure, and compromised safety. Given these costs, and the common occurrence of unexpected groundwater and pore pressure in major instability, many mining companies, including Freeport-McMoRan, have made increased efforts to understand and define the factors that often cause field pit slope groundwater conditions to significantly deviate from those specified or required within the slope design. On this basis systematic evaluation and management of risk associated with unplanned or unexpected groundwater in-pit slopes may be completed. This may be used to implement proactive mitigation measures with the aim of reducing the possibility of groundwater driven slope instability. 


\section{$2 \quad$ Key factors}

There are wide-ranging reasons why actual field groundwater conditions may strongly differ from slope design requirements. These range from the level of hydrogeologic understanding of site conditions, through the level of rigour in depressurisation program planning and implementation, and, the level of priority and commitment to the program by the site-based team.

Based on industry experience and author opinion, a set of broad categories that most commonly contribute to unplanned or unexpected groundwater pressures in-pit slopes are defined as follows:

1. Hydrogeologic uncertainty.

2. Interaction with mine process activities.

3. Predictive model reliability.

4. Hydrogeologic and geotechnical integration.

5. Monitoring and reconciliation.

6. Operational execution.

7. Resources and sustainability.

\subsection{Hydrogeologic uncertainty}

Incomplete knowledge of the mine area hydrogeologic system is a common reason why groundwater conditions in the open pit and the slopes are unexpected or uncompliant with the slope design requirements. Normally it is only possible to evaluate and predict potential ranges of pit slope pore pressure for current and future conditions, and to plan and implement a fit-for-purpose mine dewatering and pit slope depressurisation program if there is an adequate conceptual hydrogeologic model of the site. There are publications (Beale \& Read 2013; Dowling et al. 2011) that provide guidance for the types and quantities of field characterisation and data required to support an adequate conceptual model for mine dewatering and pit slope depressurisation planning and implementation purposes. Some typical hydrogeologic uncertainties that are most typically unplanned pore pressure conditions include:

- The hydrogeologic role and behaviour of major structures and structures that are important to the slope design. In particular, structure subparallel to the slope that may create stair-stepped or differential pore pressure conditions.

- The location of the main groundwater domain and compartment boundaries and the extent to which small and large-scale anisotropy will propagate and limit hydrogeologic responses to proactive dewatering and depressurisation efforts. Different types of dewatering and depressurisation response may occur given ranges of hydraulic conductivity and degrees of anisotropy, applicable at sector and pit wide scales.

- Groundwater pressure development and response to proactive depressurisation in extremely low $\left(1 \times 10^{-7} \mathrm{~cm} / \mathrm{sec}\right)$ to ultra-low $\left(1 \times 10^{-9} \mathrm{~cm} / \mathrm{sec}\right)$ conductivity bedrock. This is a significant challenge for many large open pit mines that are deepening and expanding into these types of materials. Currently, the 'catalogue' of experience of depressurising major slope sectors in ultra-low conductivity material is limited. But may mines will face this challenge as part of ongoing deepening and expansion.

- Depth dependent hydrogeologic characteristics. Many large open pit mines are not uniform with depth. However, there is a tendency for characterisation work to be limited to the shallower depth or elevation ranges of the planned mine due to drilling and characterisation costs and constraints.

- Source of recharge and the role of recharge. This tends to be overlooked or under characterised. However, a recent confidential study suggested that over half of all major slope failures where 
water is a significant contributing component are due to a local source of recharge which could include routing of local runoff, snowmelt or a minor local feature.

- The presence of perched groundwater in the pit slope up-above the main watertable in the system. This can be due to 'water left behind' on horizontal hydrogeologic barriers such as bedding or sills, or due to ongoing recharge from above, near the crest of the mine.

\subsection{Interaction with mine process activity}

Many mature and older generation mines become constrained for space to place facilities. The expanding pit crest line and facility footprints often unavoidably encroach. It is commonplace for mine facilities and process activities near the pit crest to leak water or process solution into the underlying bedrock, which can become an unintentional source of recharge to the adjacent pit slopes at either a very local scale or broader sectorwide scale. Figure 3 shows an example of leach stockpiles and solution collection ponds located in close proximity to a pit crest. Typical sources of bedrock recharge and pore pressure resulting from mine operations and process activity include:

- Stockpile leaching activity.

- Tailings storage facilities.

- Crusher pockets and water stands.

- Runoff and stormwater detention basins.

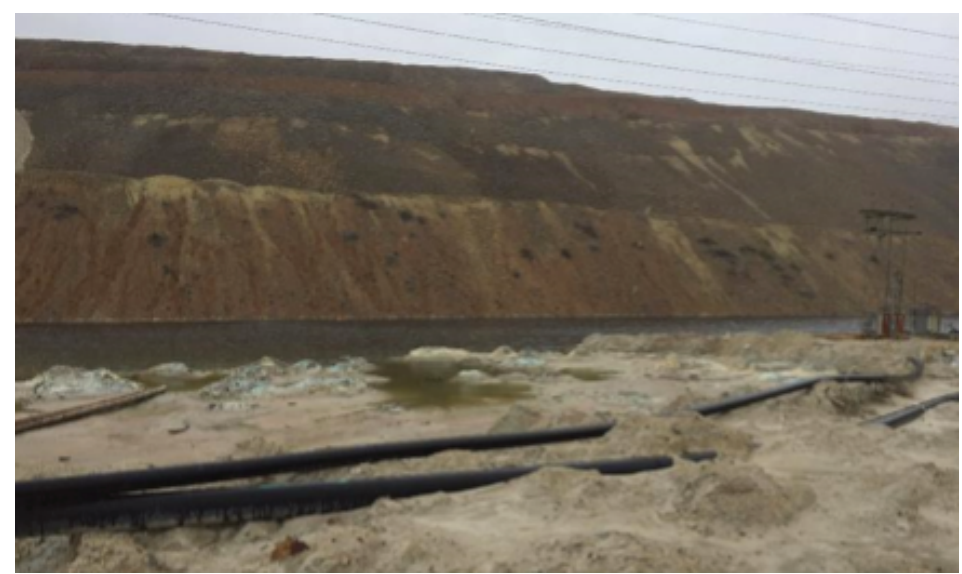

Figure 3 Process solution collection facility located immediately above a major pit slope sector

\subsection{Predictive model reliability}

A predictive numerical model is normally an important part of the dewatering and pit slope depressurisation program, and is necessary to:

- Evaluate hydrogeologic conditions as the mine phases are incremented, deepened and expanded into the groundwater system.

- Predict pit slope pore pressure conditions during the implementation of interim phases and for the final slope design.

- Define rates of groundwater inflow during mining.

- Evaluate the possible performance of mine dewatering and pit slope depressurisation system alternatives.

Depending on the level of study and support information, an empirically based predictive model can be developed based on site experience and prior mine dewatering and pit slope depressurisation results. However, in most circumstances, a numerical groundwater flow model is normally implemented to accomplish the above 
objectives. While a correctly applied numerical model can be a useful tool for predicting pit slope pore pressure and mine dewatering performance, typical over-reliance on models include:

- The issue of scale: A mine-wide model is often needed for the purposes of predicting broad mine scale groundwater inflows and groundwater levels. In recent years, mainstream finite element and finite difference code has evolved to accommodate significant sector scale refinement, geologic and structural detail within a larger mine scale framework. However, large, regional-scale models will typically not accommodate detail and produce the resolution of vertical head gradients at a mine sector scale needed to support pit slope design.

- The ability to validate predictions: Without exception, all model prediction requires validation with hydrogeologic monitoring and testing, and early-stage mine dewatering and pit slope depressurisation results. Without this, any numerical model retains a level of uncertainty with respect to the 'real-life' results that will be accomplished. Validation is normally completed via a process of peer review that requires the benchmarking of model prediction against site data and experience.

- Applied dewatering system assumptions: Many model predictions contain 'idealised' assumptions about mine dewatering and pit slope depressurisation system layouts that may not be operationally realistic within the operating mine. This can include the arrangement and timing of horizontal drains or production pumping wells, that are implemented in the predictive model in a way that could never be accomplished in reality. The results create a sense that the dewatering and slope depressurisation objectives can be accomplished, whereas they are not realistic due to the 'real-life' constraints on implementation. The 'as-built' dewatering system often does not reflect the idealised dewatering system implemented in the model.

- The use and application of numerical code: In general, the selection of model code is subordinate to both: a) having a solid conceptual hydrogeologic model of the site; and b) the ability to validate any model prediction with site data and experience.

- The application of sensitivity analysis: Hydrogeologic sensitivity analysis is normally only useful when data or conceptual site knowledge is available to constrain the variables. Often, hydrogeologic parameter uncertainties create minor change in modelled pore pressure results compared to operational implementation delay or failure, or to non-analysed change in the mine plan or sink rate. A sensitivity analysis should consider these factors.

\subsection{Hydrogeology and geotechnical integration}

In many circumstances, a central objective of the mine dewatering and pit slope depressurisation program is to support and accomplish the depressurisation targets required in the pit slope design. However, in many situations the dewatering program also needs to reduce the impact of groundwater flow on mining operations irrespective of the slope design requirement, which may be considered the 'general' dewatering program. It is critically important to successful mine plan implementation that the mine dewatering and pit slope geomechanics programs are heavily integrated, from pre-feasibility level of evaluation and prediction, through mine design, operation, implementation, modification and final closure. Dewatering and geomechanical integration need to consider:

- The geomechanical slope design analysis needs to incorporate groundwater pressures that are achievable within the bounds of both the hydrogeologic certainty and ability for the mine to implement a realistic mine dewatering and pit slope depressurisation program.

- The slope design analysis needs to identify the 'critical year' within the mine plan or pushback sequence whereby the FoS becomes dependent on proactive depressurisation. This needs to be guided by the input of valid groundwater prediction. 
- The pit slope pore pressure monitoring (piezometers) and depressurisation system design need to be laid out, designed and implemented to accomplish the pore pressure regime required for the critical year and subsequent years through Life-of-Mine.

- The mine dewatering and pit slope depressurisation predictions should provide guidance to the geomechanical design analysis. In some cases, this may include constraints and limitations on the reasonably achievable ranges of watertable and pit slope pore pressure ranges that can be attained given the hydrogeologic conditions and the realistic possibilities for implementing proactive depressurisation.

- Ultimately, the pit slope design group and hydrogeology team should establish a set of groundwater pressure targets for each major design sector that supports the slope design criteria and are reasonably achievable within the bounds of hydrogeologic certainty and the ability for the mine to reliably implement and operate proactive dewatering and slope depressurisation.

- The mine dewatering and hydrogeology program will always and inevitably require a stand-alone program of monitoring and evaluation. However, there should always be a close collaboration with the slope design team to establish pit slope pore pressure monitoring (piezometers) and reporting.

\subsection{Monitoring and reconciliation}

Groundwater level and pit slope pore pressure monitoring are critical in any pushback where the design and pit slope performance contains a prescribed groundwater condition. In the absence of field monitoring data, it is not possible to reconcile actual pit slope groundwater levels and gradients against the requirements of the pit slope design. Therefore, a piezometer network is essential and needs to:

- Be considered a routine part of the mine operation and pit slope monitoring system, almost always requiring a rolling year-on-year program of replacement.

- Include installations in all domains that have prescribed groundwater levels and pore pressure conditions within the slope design.

- Involve routine recording of groundwater levels (several times daily) and be connected to a database and workflow for routinely reporting time-series groundwater elevations together with target levels established from the slope design.

\subsection{Operational execution}

Often the ability for a mine to operationally implement a mine dewatering and pit slope depressurisation program to a prescribed plan is the most influential factor in unplanned or unexpected groundwater levels. Oftentimes, the mine dewatering and pit slope depressurisation system layout used in a predictive model is assumed achievable without ongoing reconciliation between the as-built and the model. However, in reality, many factors can cause the as-built system to deviate significantly from the plan and include:

- Interaction with mine operations: often the ability to drill, construct and operate wells or drains to a prescribed plan is very challenging due to the day-to-day interaction with mine operations.

- The ability to maintain dewatering pumping systems in an operating mode is always very challenging: frequently, once dewatering systems are built and in place, the ongoing ability to operate them is limited by mine operations, logistics and support.

- Downstream capacity and customer: it is always necessary for a successful mine dewatering and pit slope depressurisation program that a downstream customer is available to receive dewatering flow. This is highly location specific and dependent on the specific mine-wide water balance. In some settings, a 'bottleneck' in the mine-wide water balance and site discharge constraints can limit the ability to accomplish dewatering objectives. 
- Mine Phase interaction: is an increasingly common constraint on mine dewatering and pit slope depressurisation activities. Multiple phase pushbacks often involve a lower or inner pit phase and an upper phase of mining. This can compromise the integrity of dewatering assets and infrastructure due to cast-off and eventual mine through.

\subsection{Resources and sustainability}

A very significant reason why major pushbacks and mines, in general, are not dewatered to target levels is due to third party performance and site-level commitment to a program. So common factors include:

- The availability and performance of drillers including production pumping drilling and well construction contractors.

- The availability and lead time with parts and spares associated with mine dewatering, and in particular, submersible production pumping equipment and spares.

- Mine site procurement processes which are normally not driven by a mine dewatering or pit slope depressurisation process.

- Site team resources, organisation and accountability, which may not ultimately be focused on mine dewatering.

- Reporting: It is proven within the industry that reporting of dewatering results, on a monthly basis, through to the highest levels of management at the mine, produces increased levels of accountability and improved mine dewatering and pit slope depressurisation results.

- Reluctance to embrace technology alternatives or invest in initiatives that may have potential upside value that will pay back over time-scales that exceed budget or management cycles.

\section{$3 \quad$ Framework for assessing risk}

A consolidated mine dewatering and pit slope depressurisation review or risk matrix can be readily established to evaluate the main factors that lead to unplanned or unexpected pore pressure in-pit slopes. An example risk matrix is offered in Table 1 . The matrix covers the categories of risk and uncertainty described above. There is a systematic additional tier of criteria to evaluate the status or risk level of each category, but it is beyond the scope of this paper to describe each in detail. The objective for any mine would be to conduct an initial mine dewatering and pit slope depressurisation review with the matrix included as a main deliverable. The aim would be to identify and then take action to improve the critical risk areas and through a process of repeat review, evolve the mine dewatering and pit slope depressurisation program toward state of industry practice. Freeport-McMoRan has completed a review of all its open pit mines in the Americas and used a similar approach to accomplish meaningful improvement in the mine dewatering and pit slope depressurisation planning, implementation and optimisation process. Some specific examples are discussed in the following section. 
Table 1 Example mine dewatering and pit slope depressurisation review or risk matrix

\begin{tabular}{|c|c|c|}
\hline \multirow{2}{*}{ Main category } & \multirow{2}{*}{ Subcategory } & 5-year mine plan/Life-of-Mine \\
\hline & & Strength Opportunity Threat \\
\hline \multirow{4}{*}{$\begin{array}{l}\text { Hydrogeologic } \\
\text { uncertainty }\end{array}$} & District scale & \\
\hline & Pit scale & \\
\hline & Characterisation of major structures & \\
\hline & Hydraulic test program & \\
\hline \multirow{2}{*}{$\begin{array}{l}\text { Interaction with mine } \\
\text { process activity }\end{array}$} & Unquantified stockpile leakage impacts & \\
\hline & Surface water management & \\
\hline \multirow{2}{*}{$\begin{array}{l}\text { Predictive model } \\
\text { reliability }\end{array}$} & Predictive certainty - dewatering flow rates & \\
\hline & Predictive certainty - pit slope pore pressure & \\
\hline \multirow{5}{*}{$\begin{array}{l}\text { Hydrogeology and } \\
\text { geotechnical integration }\end{array}$} & $\begin{array}{l}\text { Groundwater pressures achievable included in } \\
\text { geotechnical slope analysis }\end{array}$ & \\
\hline & Critical year definition & \\
\hline & $\begin{array}{l}\text { Groundwater pressure targets for each major } \\
\text { design sector }\end{array}$ & \\
\hline & Proactive depressurisation program design & \\
\hline & General mine dewatering system design & \\
\hline \multirow{3}{*}{$\begin{array}{l}\text { Monitoring and } \\
\text { reconciliation }\end{array}$} & Piezometer network adequacy - in-pit & \\
\hline & Piezometer network adequacy - ex-pit & \\
\hline & $\begin{array}{l}\text { Periodicity of review of ongoing dewatering } \\
\text { and pore pressure results }\end{array}$ & \\
\hline \multirow[t]{2}{*}{ Operational execution } & $\begin{array}{l}\text { Logistics and support to build and operate the } \\
\text { systems }\end{array}$ & \\
\hline & Downstream constraint & \\
\hline \multirow{2}{*}{$\begin{array}{l}\text { Resources and } \\
\text { sustainability }\end{array}$} & Construction resource adequacy & \\
\hline & Human resource adequacy & \\
\hline
\end{tabular}

\section{$4 \quad$ Practical examples of implementing improvement}

During recent years, Freeport-McMoRan has utilised the review matrix approach at all open pit mining operations in North and South America. Utilising the approach opportunities have been identified to improve certainty in depressurisation planning and implementation. Some practical examples are discussed below.

\subsection{Hydrogeologic uncertainty and predictive model reliability: bedrock dewatering response testing in Northwest Western Copper}

In order to characterise bedrock hydraulics and reduce uncertainty in the conceptual hydrogeological model, hydraulic stress tests and monitoring were conducted in the northwest sectors of Freeport-McMoRan's Morenci Western Copper open pit copper mine in Arizona. The mine plan for the northwest sector involves a multiple phase pushback with deepening and expansion of the pre-existing wall. Groundwater levels are relatively elevated in the sector, between 200 and $400 \mathrm{~m}$ above the final planned pit floor. The rock mass is 
relatively conductive, in the $1 \times 10^{-5}$ to $1 \times 10^{-4} \mathrm{~cm} / \mathrm{sec}$ range. Significant groundwater inflow to the pit is expected as the pit sinks toward final limits over a planned period of seven years. In addition to general control of groundwater inflow, a mine dewatering program is needed to accomplish annualised pit slope depressurisation targets, needed to support acceptable slope stability criteria.

Prior to the onset of mining the northwest sector, there was limited hydrogeologic data or recent experience with dewatering and depressurising the general region of the mine. Therefore, in order to build confidence in the hydrogeologic conceptual model and the level of confidence in dewatering predictions, a first generation of bedrock production pumping wells was implemented prior to the onset of bedrock stripping. A sequence of five wells were constructed and progressively commissioned and operated. The bedrock drawdown and depressurisation responses were then measured in a network of 10 multiple-level vibrating wire piezometer strings distributed in the footprint of the planned pushback sequence. The transient drawdown responses observed in the piezometer network were used to develop an updated hydrogeologic conceptual model of the area that included refined hydraulic parameters for the major rock units, improved understanding of how the major structures control and limit the distribution of responses, and refined approximation of recharge to the bedrock system from surrounding mine facilities. An example of the bedrock drawdown responses measured in a multiple-level vibrating wire piezometer string is shown in Figure 4.
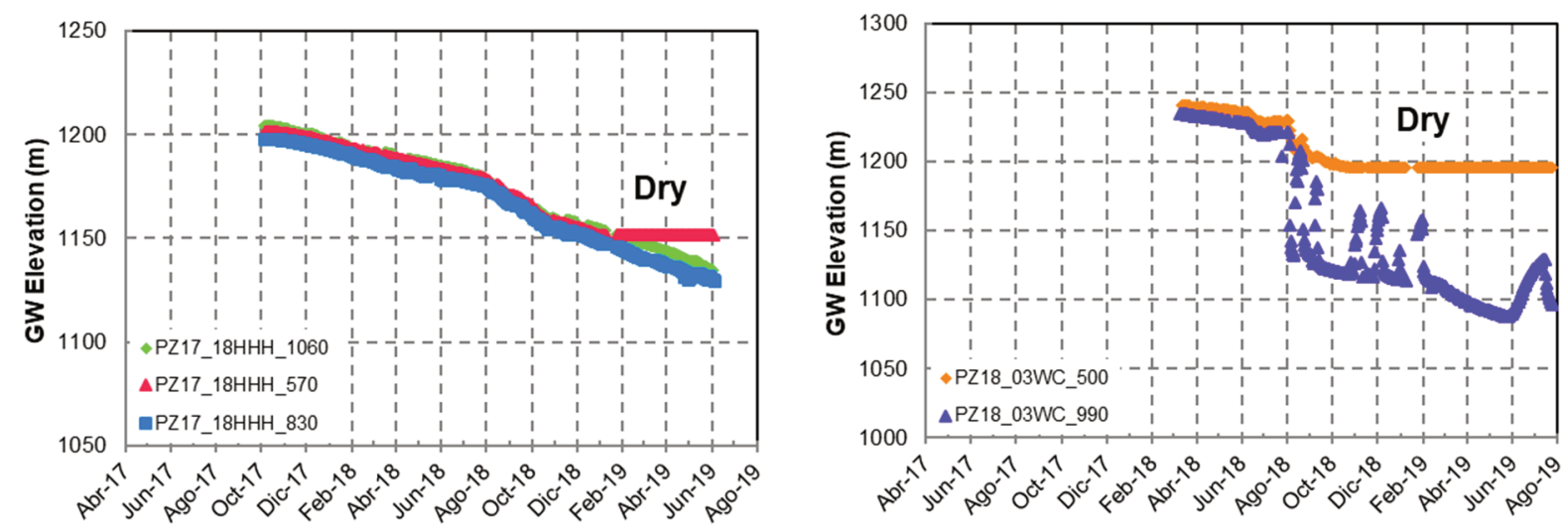

Figure 4 Example piezometer response data from the northwest sector plotted as groundwater elevation ( $y$ ) versus time $(x)$

The updated hydrogeologic conceptual model for the northwest area was incorporated into a 3D numerical groundwater flow model. A transient calibration was completed matching model simulated bedrock responses to the observed piezometer responses. A good transient match was attained. The process built additional confidence in the validity of the conceptual model and in the reliability of the numerical model. An example of the transient calibration is provided in Figure 5. The transient calibration was used to define the initial conditions for a set of dewatering predictions for the northwest sector. The model was run forward for five years with annual increments of the mine plan implemented into the model together with alternative sequencing of additional dewatering wells and horizontal drains. The results were used to select mine dewatering strategy and layout capable of maintain dry conditions for day-to-day operations, and, achieving the design depressurisation targets. The combination of hydraulic characterisation with test wells and piezometers and conceptual model update and validation with a transient calibration, provided greatly improved confidence in the predictive results and the likelihood of attaining future targets with the planned dewatering program. 

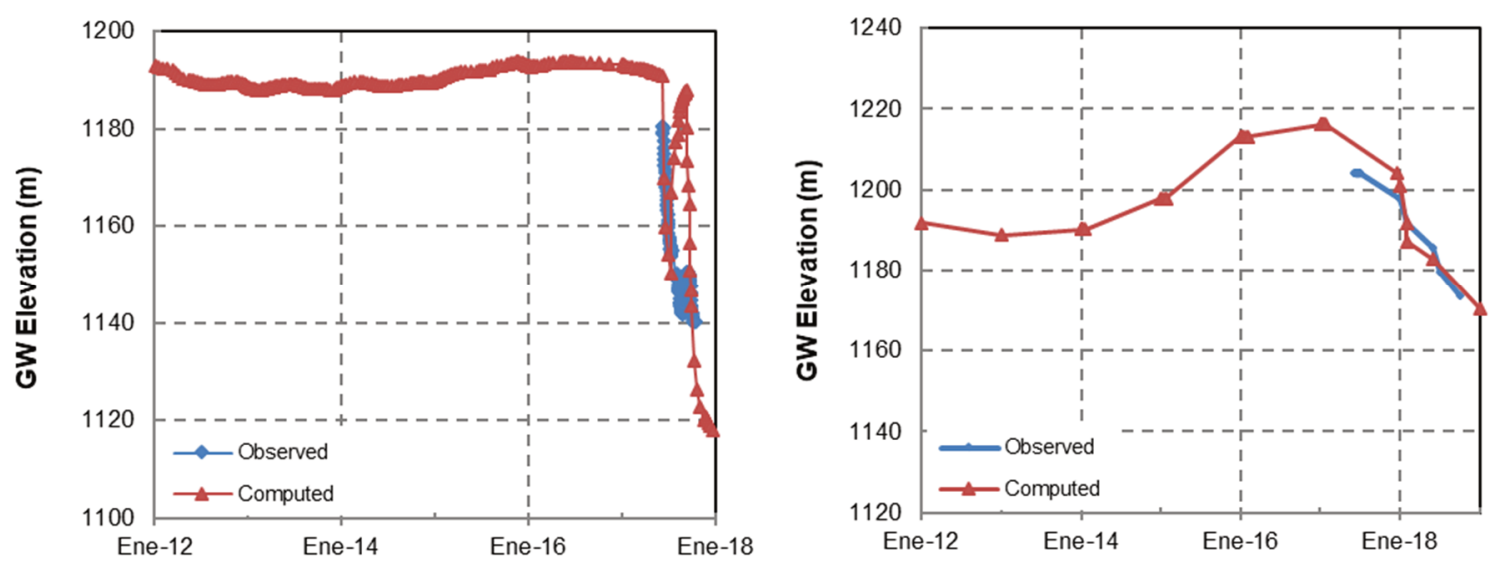

Figure 5 Example groundwater elevation versus time calibration plots with piezometer data (blue) and transient model calibration (red)

\subsection{Interaction with mine process activity: stockpile leakage impacts, perched pore pressure management with piezometric alarms}

During the period 2004 to 2015, Freeport-McMoRan's Morenci mine implemented the Garfield open pit at the north end of the mine complex. During mining, leaching of the Molinar stockpile directly northeast of the pit took place in a natural drainage sloping into the mine. As a consequence of leaching activity, perched groundwater occurred on sub-horizontal bedding in the pit slope below and down-gradient of the facility. An illustrative cross-section is shown in Figure 6. Geotechnical analysis indicated potential for instability associated with perched water on the bedding and in the rock mass above. As a risk management measure a series of piezometers were installed into the area of perched groundwater created by leaching activity. Alarm levels were set for all piezometers as the threshold above which the pit slope FoS would reduce to below 1.15. Continuous monitoring was implemented during mining and leaching activity. Leaching activities were periodically suspended when pit slope pore pressure alarms were raised via the piezometer network.

A

SECTION 205-1

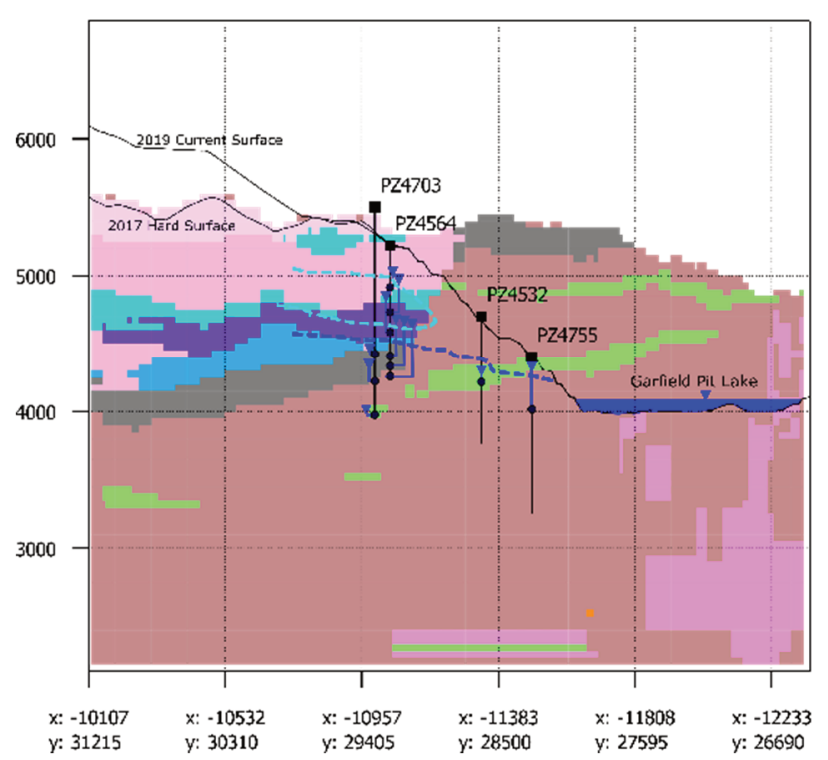

(a)

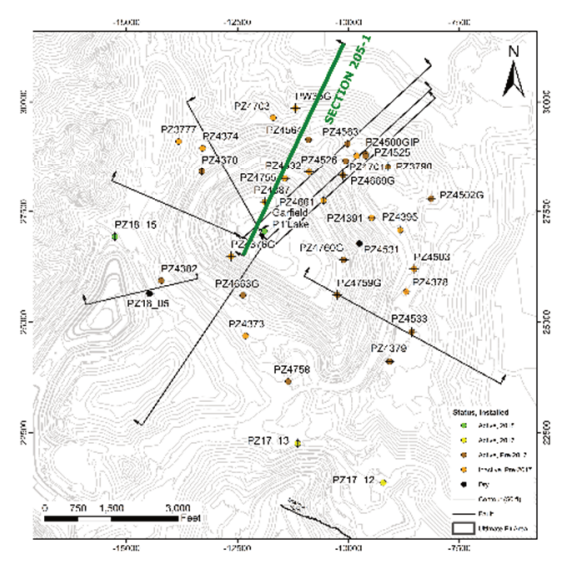

(b)

Figure 6 Cross-section through the Garfield northwest pit slope and Molinar stockpile showing piezometer monitoring, perched and deep system groundwater surfaces. (a) Hydrogeologic section; (b) Location map of cross-section 


\subsection{Interaction with mine process activity: perched process water}

A good example of slope instability influenced by perched water level is available for a confidential site, discussed below.

On the northeast wall in the pit, perched water is caused by a combination of factors, including recharge from water management facilities, tanks and pipes on the surface. Structures subparallel to the slope in combination with argillic alteration work as hydraulic barriers support perching of water.

Mitigation for the instability was drilling of drains to target the perched water. Figure 7 shows the displacement recorded by radar over the course of one year, perched water level observed in piezometers and flow in the horizontal drains in this sector. There is a correlation between a reduction of slope displacement and perched water levels. This demonstrates the benefits of drainage and reduction of pore pressure of perched water in improving slope performance.

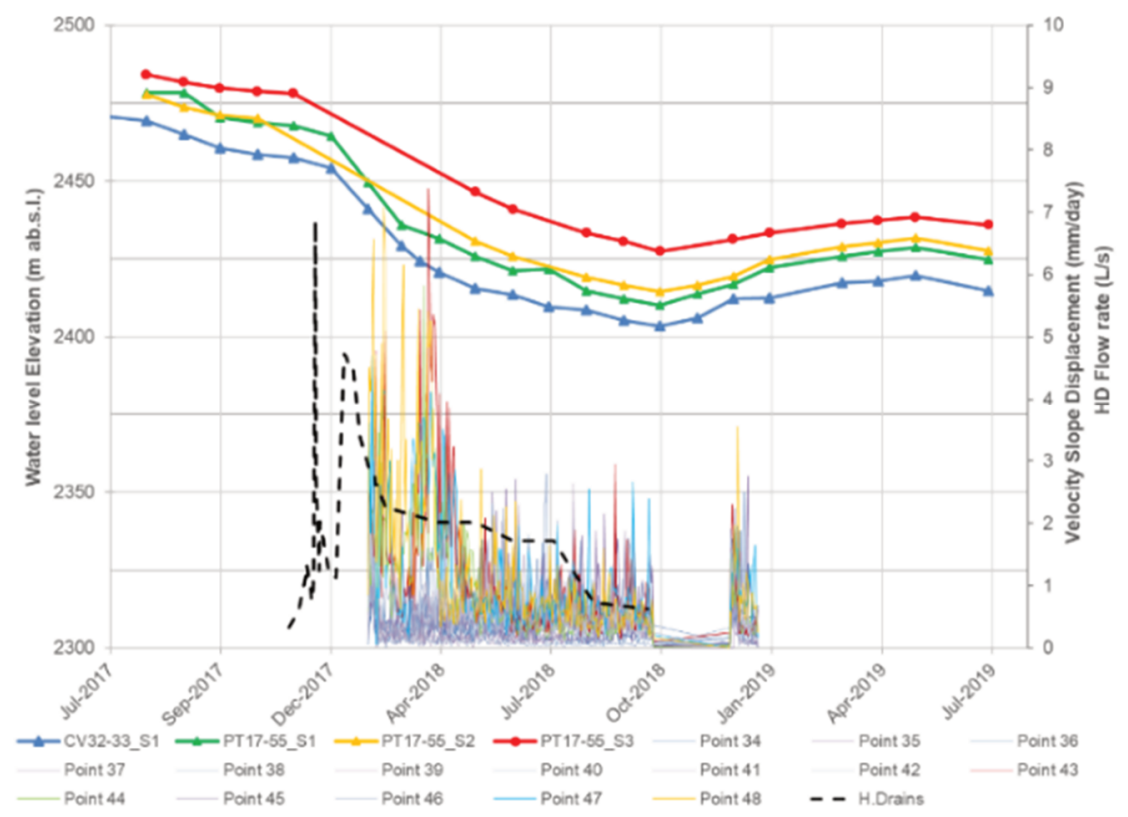

Figure 7 Slope displacement and perched groundwater level trends

\subsection{Hydrogeology and geotechnical integration: critical year definition and depressurisation system design}

A good recent example of successful hydrogeologic and geomechanical program integration is Morenci Western Copper open pit mine at Morenci, Arizona. The mine dewatering and pit slope design planning and design processes were run with a fully integrated approach that involved:

1. Developing annualised 3D pit slope design analysis in FLAC3D.

2. Generating pit slope depressurisation targets from FLAC3D needed to maintain a target FoS of 1.2.

3. Evaluating mine dewatering system performance and ability to match or exceed the depressurisation requirements with a 3D groundwater model.

4. Using the comparison between the dewatering model and pit slope design requirements to define sectors through time where more depressurisation efforts are likely needed or where the design targets may be challenging to accomplish.

Figure 8 presents a heat analysis where the groundwater flow model prediction of future depressurisation is integrated with the FLAC3D pore pressure field required to meet the design criteria, for the mutual slope geometry and time period. Cool colours depict where proactive depressurisation can accomplish the geotechnical depressurisation target. Warm colours indicate where the depressurisation system does not 
create compliant conditions. Using this approach, the dewatering and slope depressurisation system layout has been adjusted and focused on the sectors that need the largest increments of additional drainage and dewatering effort to create compliant pore pressure conditions. As illustrated in Figure 8, the left side plot shows a dewatering system with minimal measures, whereas the right plot is based on optimising the location and timing of pumping wells and drains guided by the integrated analysis. This is proving a highly successful workflow for mine dewatering and pit slope depressurisation planning and implementation, tied to slope design targets, at Morenci.

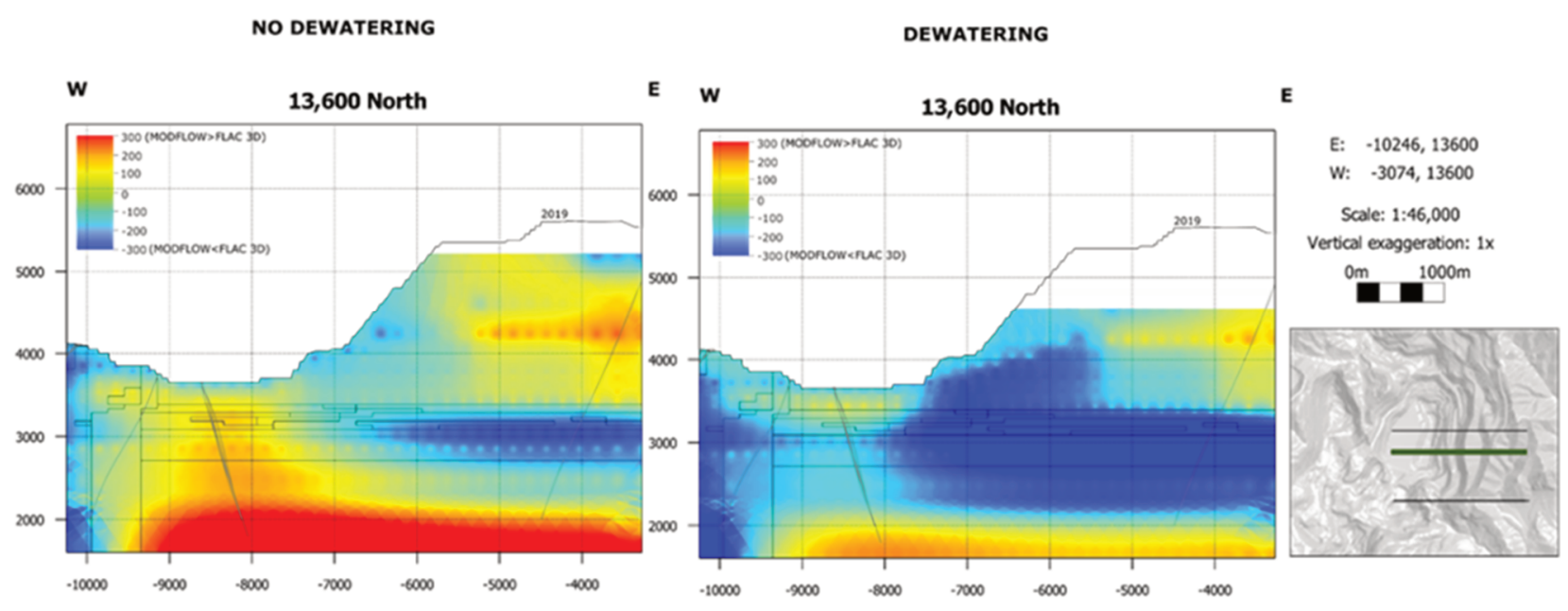

(a)

(b)

Figure 8 Heat map analysis comparing geotechnical depressurisation targets and predicted pore pressure ranges with different levels of proactive dewatering effort. (a) Dewatering system with minimal measures; (b) Optimised dewatering system

\subsection{Resources and sustainability: construction and resource adequacy and optimising dewatering production pumping performance}

The Western Copper mine dewatering and pit slope depressurisation program at the Freeport-McMoRan Morenci mine heavily depends on accomplishing targets via bedrock production pumping wells, including up to 10 in-pit installations. The hydraulic conductivity ranges and distributions of domains and compartments in the major pit sectors mean the depressurisation program is amenable to a production pumping approach provided the wells are placed within each of the main in-pit domains. While the pit area hydrogeology and expected ranges of dewatering response to pumping are well constrained, the main risk in accomplishing drawdown targets was considered by Freeport-McMoRan Morenci to be implementation and sustainability of well operation within the active mine. In order to address this risk, the mine established a target based monthly dewatering reporting protocol for the dewatering well program, including sector-based flow targets, dewatering well availability targets (percent of time running), and actual performance relative to target. The monthly report is delivered through to the highest levels of management at the mine, and, has produced significant accountability for dewatering results. The dewatering production pumping operation has ramped toward targets as illustrated in Figure 9. 


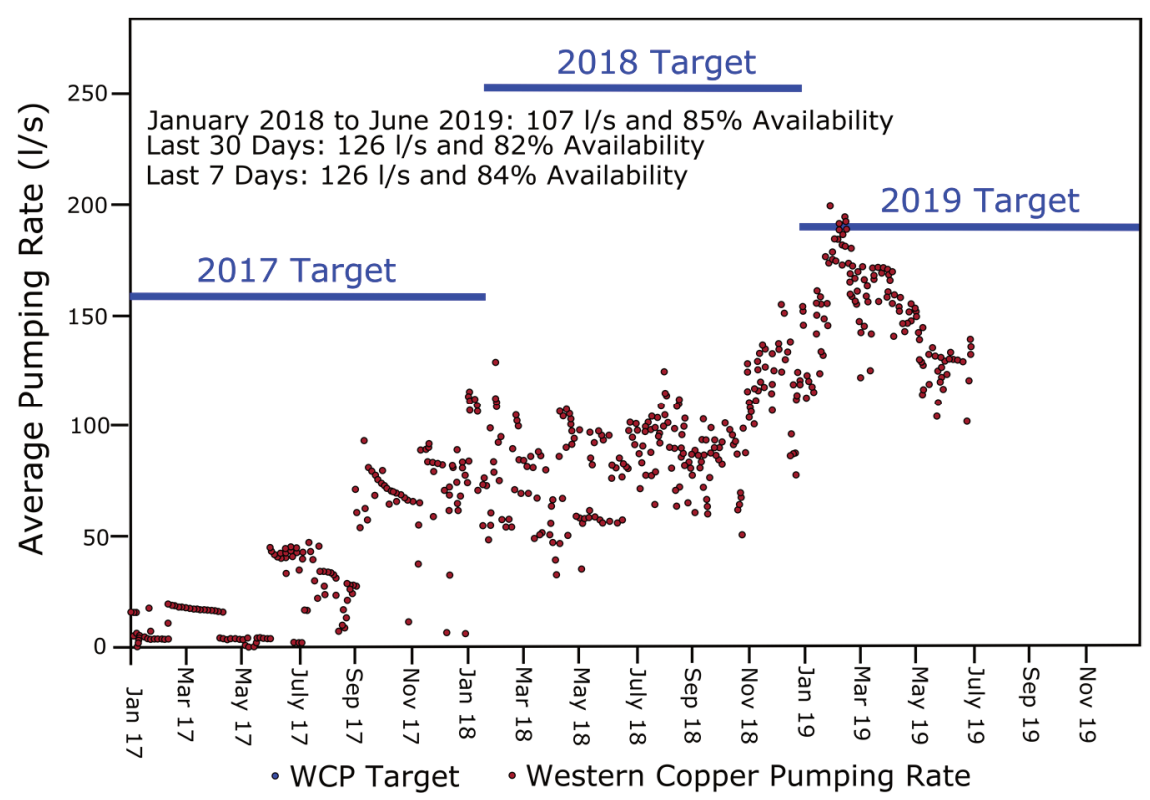

Figure 9 Target and accomplished dewatering flow for the Western Copper bedrock production pumping wells

\section{Conclusion}

Groundwater pore pressure is commonly a determining factor in-pit slope design and performance and is one of the main causes of instability. There are certain factors that can collaborate to produce the presence of unexpected high pore pressures, leading to instability or costly remediation measures that may include slope redesign. These factors have been categorised into a matrix in a way it can be used as a management tool to analyse the groundwater and depressurisation factors that may lead to unexpected pore pressure conditions. These categories extend through adequate hydrogeology characterisation, depressurisation system design, geomechanical integration, operational execution, implementation and monitoring of proactive depressurisation and drainage systems. Practical implementation of the review matrix can lead to identification of opportunities to improve the pit slope depressurisation program.

\section{References}

Beale, G 2018, 'How our understanding of water and slope stability has improved since 2009', Proceedings of the 2018 International Symposium on Slope Stability in Open Pit Mining and Civil Engineering, Asociacion Nacional de Ingenieros de Minas and Colegio Oficial de Ingenieros de Minas del Sur, Seville.

Beale, G \& Read, J 2013, Guidelines for Evaluating Water in Pit Slope Stability, CRC Press, Boca Raton.

Dowling, J, Beale, G \& Reidel 2011, 'A Framework for Mine Dewatering and Pit Slope Depressurization Design and Implementation', in E Eberhardt \& D Stead (eds), Proceedings of the 2011 International Symposium on Rock Slope Stability in Open Pit Mining and Civil Engineering, Canadian Rock Mechanics Association, Vancouver.

Read, J \& Stacey, P 2011, Guidelines for Open Pit Slope Design, CRC Press, Boca Raton. 
